\title{
Searle's theory of proper names, from a linguistic point of view
}

\author{
Michael J. Evans/Rainer Wimmer \\ (Heidelberg/Mannheim)
}

\section{Introduction}

There has been a long and great tradition, in philosophy as well as linguistics, of inquiry into the functions proper names fulfil in any linguistic community. Philosophical questions differ in many respects from what linguists are interested in and from what they think to be relevant for the ordinary and everyday use of proper names. Philosophers' attention is strongly focussed on the question of what role proper names have to play in relating facts of the actual world to linguistic expressions, often called linguistic signs by linguists.

Proper names seem to be those linguistic entities most specifically suited to fulfil and guarantee an unmistakably established and constant relation between a given phenomenon in the world on the one hand, and a linguistic sign or the use of a linguistic sign on the other. What the relation is between the world and a language or, more specifically, certain signs of a natural language, has been the dominant question in the philosophy of proper names for the last century (cf. Dummett 1973, 54 ff.). John R. Searle has made important and prominent contributions to the solution of this problem (cf. Searle 1969, $157 \mathrm{ff}$; 1983, $231 \mathrm{ff}$.). His proposals for describing and defining the function of proper names in a natural language have been widely accepted by linguists.

In linguistics, and especially in the field of onomastics there has been a serious lack of reflection on the theoretical problems associated with proper names (for the situation in Germany, see e. g. Debus 1980), so that proposals made by Searle and other philosophers have been readily welcomed, at least as a basis for further discussion. In the following remarks on Searle's theory of proper names from a linguistic point of view, we shall try to pay due heed to the fact that the issue has for a long time been dominated by philosophical questions and aims. These questions and aims will not be disparaged as minor or irrelevant from our linguistic 
point of view; but it will be necessary to say that a linguistic treatment of proper names requires a somewhat different view of the topic than philosophers usually supply.

We do not want to say that the main questions which philosophers usually think of as constituting the "problem of proper names" (namely questions about the possible referential use of proper names) have not been treated exhaustively in language philosophy. On the contrary, as far as we can see, the problem of reference by means of proper names has been extensively discussed, so that there is hardly any conceivable aspect which has not been considered and reconsidered (cf. Schwayder 1961 passim; Linsky 1967 passim). But the purely referential function is not the only one that proper names have in a natural language. Other aspects of these names are important for linguists, as we show below, but philosophers, including Searle, do not pay much attention to them. Consideration of at least some of these other phenomena, while possibly raising a few more problems for the language philosopher, would certainly help towards a better appreciation of the nature of proper names, and promote interdisciplinary understanding also.

\section{Proper names}

Writers in philosophy and philosophical logic differ considerably from ordinary language users and the linguists who study them in their conceptions and definitions of what a proper name is.

A major difference between philosophers and linguists, as will be shown below, centres on the understanding of the designative relation holding between proper names and single definite objects. But we show that neither the relation, nor the two entity-classes in the relation, are unproblematic.

One of the key issues, for example, is the level of generalization at which statements, descriptions and analyses are intended to apply. Linguists are inevitably interested in whether the designative relation is thought by philosophers to hold between the proper name as an abstract type of a sign, or between the name in use (i. e. as an actualized token of its signtype) and the object meant. ${ }^{1}$

1 The nature of the object, too, needs close scrutiny of a similar kind: we can imagine that every object known is in some way or other unique, simply because no two objects can occupy the same segment of space-time in a universe, and we know objects by virtue of their relations to other objects in that universe. However, humans beyond a certain age in childhood spend much of their time grouping objects on the basis of various characteristics that they are perceived as sharing: it is then possible to see an individual object on an occasion as a situationally bound token of its category type. 
Should the designative function of proper names be described as a general phenomenon of a community's language (langue in Saussure's terminology) - or as part of an individual's language use or speech (Saussure's parole)? A number of interesting consequences for linguistic description and analysis follow from this decision (cf. Sørensen 1963 passim; Lyons 1977, 174-229) and are not without relevance for philosophers.

The decision on generalization will, for linguists, determine whether proper names have to be regarded as part of the lexicon of a language, or as a nonce speech phenomenon dependent on specifiable situations of language use. Proper names are generally not to be found in ordinary dictionaries but there are special dictionaries for different kinds, such as family names, place names, etc. This reflects the common opinion of linguists: proper names are types of linguistic units, and part of the lexicon of a language, but are semantically different from so-called appellative words (roughly corresponding to common nouns), so that we need different techniques and kinds of description for the meanings of proper names versus appellatives.

\subsection{Proper names in philosophy}

There is a widely accepted and prominent definition of a proper name. That given in Frege $(1966,54)$ says that any linguistic expression counts as a proper name, provided that it is used to designate one and only one definite object. A linguistic expression can have any one of a large variety of different forms. It can be an individual's name like Fred or Baker; it may contain no name, but instantiate the grammatical structure of a noun phrase (NP), as in the tallest man in our town or the woman I met yesterday at 12 o'clock.

Of course, several variations of this conception of proper name exist in the literature (cf. Wimmer 1973, $77 \mathrm{ff}$.). However, they all emphasize that there should be a single definite object designated by a proper name and that there should be a well established and fixed relation between the linguistic expression and the object meant.

In contemporary philosophical thinking on the problem of proper names we still find the reflections of a continuing tradition following on from Frege's view. Russell's analysis of proper names, being within the tradition, is compatible with Frege's view. Where Searle comments on proper names, he focusses on their referential function. Though he has a more restricted conception than Frege of what constitutes a proper name, his disregard for the differentiations that linguists have proposed on the syntactic and semantic complexity of proper names puts his theoretical work within the philosophical mainstream of the last hundred years. 
Frege's main question was: How do proper names function in statements, so that truth-values can be assigned without difficulty to statements containing such names? His answer was: in philosophy only those linguistic expressions and/or speech events can be accepted as proper names, which guarantee the existence of a fixed relation to objects in the world. In this conception, Fregean proper names appear in a mediating role between sentences and their truth values on the one hand, and objects in the world on the other.

Following on from Frege, Russell presented his analysis of proper names in 1905. The Russell analysis has two core assertions. (1) [Our example] A proper name like Jobn $R$. Searle has to be analyzed as a definite and unambiguous description of a person, whom we all know as a philosopher, who has been professor of Philosophy at the University of California at Berkeley since 1959, etc. (2) The linguistic units which best fulfil the function of a proper name are deictic items, e.g. the pronominal this or that, because such items, as well as others, when used in a non-fiction situation guarantee an immediate acquaintance with the object meant. To put this in Searle's terminology, we would say that there is a virtually unmistakable intention on the speaker's part to refer to and identify one and only one object.

In the Frege-Russell tradition there has been a change in the value accorded to linguistic facts about proper names. In several publications Strawson has offered linguists hope that the characteristics they have found among proper names in natural languages would find more consideration than previously in philosophical debate on this topic. Strawson has emphasized that linguistic categories should be taken into account; philosophers should also consider the use of proper names in a natural language as a factor in determining how relevant both reference and definite descriptions are to the relation between language and world. But Strawson's message was not heard or accepted. There is still a deep gap between philosophers and linguists on proper names in natural languages: on the one hand, firm preconceptions in philosophy as to what they are; on the other, what linguists count as proper names and/or proper nouns.

It is an important point for Searle (cf. Searle 1983, ch. 9) to say that reference by means of proper names includes the use of descriptive information about the referent. When a speaker uses a proper name referentially, some kind of knowledge about the person or object meant is always implicated. This descriptive knowledge need not be essential for securing the referential relation: it may even be rather unimportant or peripheral in respect to the referent. In Searle's view it is only required that there is some descriptive content which helps speakers to accomplish their intention to refer. For him, it is a relevant aim to integrate his theory of reference into a theory of intentionality: i. e. everything that speakers 
know semantically is also relevant in fulfilling the intentions they have in mind.

All these aspects of Searle's theory of proper names can be regarded as uncontroversial from a linguistics viewpoint. No linguist nowadays has any doubt that there is at least some connotative, historical/etymological or social content associated with the use of common names.

The thrust of Searle's argument on descriptive content is mainly directed against Kripke's theory of "causal chains" (cf. Kripke 1980), which says that in fixing the reference of a name, there might be room for a descriptive or predicative content securing the act of baptism or naming, but that from the moment the referent is fixed - there is only a causal or communicative chain which secures the correct use of a proper name. In short: the fixed referential relation between a name and a certain object is transported only by direct communication from one speaker to another, almost without using any intermediate descriptions.

From a linguistic point of view, there is no contradiction between Searle's and Kripke's positions, but only a difference of interest. Kripke is mainly interested in the act of fixing the reference, whereas Searle wants to emphasize that some descriptive content always remains to help secure what one might call a "fully consummated reference".

\subsection{Proper names in linguistics}

The treatment of proper names in linguistics is somewhat different. To begin with, the objects which linguists taxonomize as "proper names" form a large number of sets related to each other in quite complex ways, so that proper names might be regarded as itself a name for a superset.

This fact is further complicated by the presence of two linguistic labels, proper names and proper nouns, which have sometimes been used synonymously in the literature and sometimes not, a tradition which in the logical treatment of grammar goes back at least as far as Thomas Wilson (1551) or the even earlier semantic classification of nouns adumbrated in Linacre (1533) (cf. Padley 1976, 41). Ultimately, it depends on the polysemy of the Greek word onoma, found in the work of the second-century B. C. grammarian Dionysius Thrax.

Nowadays, for example, Crystal $(1980,288)$ suggests that proper noun is a grammatical term mainly contrasting with common noun, while proper name, "The alternative term [...] reflects its traditional SEMANTIC definition: the name of an individual person, place, etc.". Alexander $(1988,38)$ makes no distinction: "A proper noun (sometimes called a 'proper name') [...]". On the other hand, both Huddleston $(1984,229$ f.) and Quirk, Greenbaum, Leech and Svartvik (1985, esp. 288-96), distinguish between the terms very carefully. Proper noun labels a grammatical class of single 
words that may alone or in construction with other words (of the same or different class) be used as names. Names, however, can be of indeterminate length, although a name "normally functions as a single unit with respect to grammar" (Quirk et al. 1985, 288).

At least three important facts need to be made explicit here. Firstly, noun is a term of grammatical (syntactic) description and analysis, while name relates to situations of use which can be described and analyzed macrolinguistically and microlinguistically from (a) the semantic and (b) the pragmatic point of view. Secondly, to continue the traditional subclassification of nouns into categories such as proper and common perpetuates the centuries-old tendency to confuse syntactic with semantic criteria in grammatical description. We have nothing against mixed criteria per se, but it is important to draw attention to such mixing when it occurs. Following from this view comes our third point: we would like to see name as a semantico-pragmatic entity, being distinguished from grammatical structure types whose tokens, when uttered, can be used as a name. This is not an established distinction in the literature, but will help to clarify our discussion. We shall therefore distinguish, in what follows, between various types of name and sets of related - and linguistically describable - namestructures.

\subsubsection{Proper nouns and proper names}

It is difficult to assert with any conviction that proper nouns as a class can be defined on the basis of their common grammatical, and more specifically syntactic characteristics - although one can discern subclasses in this way (cf. Wimmer 1973, $122 \mathrm{ff}$.).

As Quirk et al. (1985, 288 and 245) point out, an important characteristic of proper nouns in English is that they frequently lack "article contrast". The examples given, namely:
Paris
* the Paris
*a Paris
* Hague
the Hague
$*_{a}$ Hague

immediately show confusion, since the second cannot be a proper noun. Rather, it is a name-structure containing a proper noun as one of its elements. The other element is in this case a definite article, but other kinds of accompaniment can be found before or after the proper noun. An important class of these is called descriptors by Quirk et al. - an appeal to semantic criteria: they look like members of the set of common nouns in English. For example in Senator Morse and Dallas Road, Senator and Road are descriptors. It is not clear if in King's College, another of the names they give, Quirk et al. wish College to be classified in the same way.

Descriptor is evidently not a syntactic category, since it has neither a unique form-class membership nor a single "slot" for itself in the namestructures of which it is a part. Rather, the term appeals to semantic and 
pragmatic facts about the meaning of names, which we shall pursue in more detail below. It would seem that in English the descriptor, if a noun, can frequently be drawn from the set of common nouns, giving a structure: proper plus common noun (either PN-CN or CN-PN). Intriguingly in such nominal structures, there is no a priori syntactic method for determining their "headedness". Nor, for those structures which are headed (i. e. endocentric), can one predict whether $\mathrm{PN}$ or $\mathrm{CN}$ will be the head: take names like Hyde Park, Park Lane, Richmond Palace and Crystal Palace, for example.

The class of proper nouns is difficult to isolate clearly from that of common nouns. As Quirk et al. show, "a number of common nouns with unique denotation are close to proper nouns" (op. cit., 288) and their written forms sometimes start with a capital letter, e. g. Earth. Conversely, proper nouns are sometimes found to lack the "unique denotation" that is their general hallmark. When this happens, their characteristic restrictions on number contrast and determination are relaxed. Examples: The Dianas are becoming very numerous; I once knew a Diana; The second famous Diana in history is better known to Britons than the first. If we assume that denotations should be listed in the lexicon that linguists establish for English, such facts are problematic.

No less problematic, but situated at a different level in the linguistic analysis of English and other languages, is the fact that even when "unique denotation" might be seen as maintained, the expected restrictions on syntactic structure do not apply across the board. This has frequently been the source of confusion in linguistics handbooks that discuss endocentricity. For example, in Premodifier + Head Nominal structures (of the type old girl) that are singular, there is no rise in status to the rank of NPSubject or NP-Object without the addition of a word-form of Determiner type, viz.

*Old girl went home / *We met old girl

The lan old girl went bome / We met the /an old girl

Nor can the noun Head alone rise to NP status, if the noun is one of the class Common:

*Girl went home / *We met girl

Compare this with examples such as the following (fictitious Exciting Sun exclusive!):

Radiant Diana potted ber baby in one

The/a radiant Diana potted ber baby in one

and:

Enthusiastic crowds clapped radiant Diana

Enthusiastic crowds clapped the/a radiant Diana 
The Head noun can rise to the NP status if classed as Proper:

Diana potted her baby in one Entbusiastic crowds clapped Diana

In contrast to this, nominals whose tokens are used for vocative purposes, and are structurally describable as appositive to simple sentences in a way similar to sentence adverbials, have raising restrictions reversed - always assuming that this position is to be designated as an NP rather than just a Nominal "slot" (cf. Quirk et al. 1985, 773-5).

Compare: Old girl, this is wonderful news

I say, old girl, everyone has gone bome

Everyone went home, old girl

with: $\quad *$ Radiant Diana, this is wonderful news

* I say, radiant Diana, everyone has gone home

* Everyone went home, radiant Diana

On the other hand, it does look as if the neatness of the dichotomy vanishes when the question of the noun Head rising alone to NP is considered: both

\section{Girl, this is wonderful news}

and Diana, this is wonderful news

are instantiated in the grammar of English, and the corresponding second and third structural tests from the above are also passed by both types of noun. The vocative function seems thus to be performed by using either proper or common noun tokens in English, but not in quite the same way.

\subsubsection{Proper names and definite descriptions}

The term definite description (cf. Russell 1956) has now found a place in at least one grammatical description of English (cf. Quirk et al. 1985, 294), where it is partly contrasted with names along a gradient of difference. The examples used show that Russell is the unacknowledged source: Sir Walter Scott is a name, and the author of Waverley is a noun phrase which is termed a definite description. The distinction is that

Both names and definite descriptions have (situationally) unique denotation; but one of them is grammatically 'frozen', while the other is formed according to the normal productive rules for constructing definite noun phrases. The most obvious indicator of a name is its spelling with initial capitals; while the most obvious indicator of a definite description is its initial definite article. Expressions which combine both these features, such as the Eiffel Tower, are neither completely name-like nor completely description-like, but somewhere between the two. (Ibid.)

We can see a mixture of criteria used here. Unique denotation, if situationally determined, will be a matter of pragmatics (and parole?). Grammatical "frozenness", a characteristic which is not by any means as clearly defined 
as one would wish, is presumably a matter of system syntax and thus of langue. Spelling introduces orthographic convention and relates to forms of graphemic expression that are irrelevant for the spoken language and are a matter of taught social convention (a sub-aspect of langue?). The final point, that all definite descriptions start with a definite article, introduces a semantico-grammatical category which could be viewed as either generally systematic or situationally and discoursally determined, and thus relating to either langue or parole: in any case it is too restrictively formulated, since "the-ness" can be expressed in other ways than by the use of the definite article (e. g. by possessive pronouns, deictics, and other determiners).

Quirk et al. $(1985,294-5)$ propose a four-segment "gradient between descriptions and names", as follows:

(i)

(ii)

(iii)

the Oxford road

the Oxford Road

Oxford Road

(iv)

Oxford

Here, (i) is a definite description that could be paraphrased as "the road that leads to Oxford"; in (ii) the description is "conventionalized to the extent that Road is capitalized, so that the whole makes a composite name" - again the criteria seem to be graphemic, but surely this must reflect some ongoing process in the community's everyday uses of the name, such as orientation towards its referent as an independent, discernible entity in the local topology, leading to the name's first appearance on street signs, signposts and maps, etc. In (iii) "the loss of the article has taken the conventionalization further". We would prefer to say that the community has decided to do without the article altogether, and now uses the new structure as a name (which now appears in addresses on envelopes, etc.). The final example, (iv), is a proper noun used as a name, whose history is irrelevant for the present day user: "Although native English speakers may be able to analyse this into two elements ('ford for oxen'), such an analysis plays no part in their understanding of Oxford as the name of a university city." In Welsh the name for Oxford is Rbydychen ("ford" + "oxen"), so a loan translation can be assumed one way or the other; but this shows that at least for some part of its history, the place was designated by means of a name-structure like (iii), or even (ii). ${ }^{2}$

From the above examples, we can see that (ii) and (iii) are critical for the philosophical view of proper names and unique referents, since it does not look as if the definite article is necessary to guarantee either uniqueness or definiteness of the intended referent. We seriously question whether

2 The translatability of names is another thorny problem for linguistic theory, but we shall not go into this: cf. Coates $(1988,10)$. 
there could be any difference between (ii) and (iii) from this point of view. Quirk et al. appeal to a "scale of institutionalization" for explanation, without making clear what they mean by it. They note: "[...] there is sometimes vacillation between the use and omission of the definite article. It might be better, in fact, to regard names without articles as exceptions to the more general rule that definite noun phrases are introduced by the article the." 3

From the historical point of view it is difficult to attach any importance to the stated need for the definite article, since it is a well-known fact that in earlier times, the ancestor languages of English and German lacked such a thing. Are we therefore to suppose that the ancestral language users had no means of making definite descriptions? It seems ill-advised. We know that the present-day definite articles in both languages developed from deictic items there - indeed, dialects of German even today have a recognizable deictic (demonstrative) function associated with the definite article series. We have not seen it suggested that Frege may well have had this function in mind when talking of proper names, but if this is so, Russell's ideas on this and that come much closer to Frege than previously thought. It is also perhaps worth noting that in German colloquial styles the definite article series is often used with otherwise un-premodified proper nouns, putting them in much closer structural proximity to "definite descriptions" for Frege than would be evident to anyone reading his work in English translation. Examples would be:

Die Marion kam gestern ("the Marion came yesterday")

Wir saben den Peter auch ("We saw the Peter, too")

Er wohnt in der Märzgasse ("he lives in the March Lane")

and so on.

A second historical point can be made for the Quirk et al. treatment of definite descriptions vs. proper names. As we can see, the present-day proper noun Oxford developed from an earlier proper name structure that may in turn have evolved from a (Quirkian) definite description. However, the modern proper noun can itself be part of a definite description that will evolve into a proper name structure, as illustrated in the shift (i) $\rightarrow$ (ii) $\rightarrow$ (iii). This is a very familiar development to those working in historical linguistics: lexical attrition or wear, increasing the compactness of expression forms over time, is a normal feature of every language's evolution. It does leave us with a problem for synchronic linguistic

3 As we have already suggested above, this is not a correct formulation of the general rule for definite noun phrases. 
analyses of the modern language, however, since it prevents us from stating a consistent principle of morphological or syntactic derivation of one structure type from the other. ${ }^{4}$

\section{Problem: 'proper name' and reference}

In the philosophical discussions, the term proper name is proposed and defined on certain linguistic objects to secure the notion of unambiguous, unique reference, and is closely associated with definite descriptions and proper nouns for this purpose. As we have seen, various ways of dividing the domain are proposed, possibly so that the categories set up can be hierarchically related. However, most discussion has taken place on the basis of an atomistic, minimalist approach to analyzing language from both sides. Many of the examples treated are no longer than short sentences or parts of sentences, decontextualized. What was missing until recently was a pragmatics and discourse view of the subject.

Brown/Yule (1983), following on from remarks made by Lyons (1977, 172), have pointed out that for the analysis of ordinary language in use, the concept of reference as treated by philosophers needs further development. What is important is not so much a guarantee that a definite description - and hence a proper name in the philosophical sense - is truly applicable to the thing which it represents; much more important is that it should be an effective means of drawing the hearer/reader's attention to that thing. There is, then, a difference between correct and successful reference - reference here being used in a slightly different, linguistic sense (cf. Brown/Yule 1983, 206 ff.).

For example, if one of us were watching television, and Margaret Thatcher suddenly appeared on the screen, it would be correct for him to draw the other's attention to her by uttering any number of descriptive expressions, some of which are:

\section{Oob, look! Margaret 's on! \\ Ob, here comes our beloved Prime Minister \\ What's Margaret Thatcher doing on German television?}

The success of any of these references would depend on the listener being able to pick out the intended referent. If her face is filling the television screen, and he is gifted with normal eyesight and can turn his head in that direction there should be no problem. On the other hand, there would possibly be a problem were the picture different: if she is pictured edge of screen, in a crowd of Conservative party faithful at a post-conference champagne celebration, it may be difficult for the listener to pick out the

\footnotetext{
${ }^{4}$ For a semantic view of the problem, see Coates (1988).
} 
person meant by the first reference of the three, and he might focus on the wrong person. The reference in this case would be correct in form, but unsuccessful in its situation of use.

There are other ways of referring to the same person, which are not known or accepted by a broad spectrum of the speech community. To some people, readers originally of the satirical magazine Private Eye, Mrs. Thatcher is known variously as Tina, the Boss, or simply $M$. For members of this in-crowd and other parties to this knowledge, who could be thought of as forming a communication community rather than a speech community, these names will also be correct as references, and possibly just as successful when used among the communication community members. But for anyone outside the community, not party to their knowledge, these names are - to all intents and purposes - incorrect. They can nevertheless be successfully used for reference on occasion, e.g. if Margaret Thatcher is filling the screen and the utterance Oob, look! Tina's on! is made under the same conditions as previously, the intended referent will be picked out, even by someone from the outside the Private Eye communication community.

This, it might be argued, is not really a case of overall incorrectness, however, since some people do have access to the knowledge that makes the reference correct. But there are instances, for example of mistaken identity, where only the speaker/writer believes the reference to be correct, and everyone else in the community rejects it as incorrect. Can successful reference nevertheless take place in such circumstances? Of course it can. One has only to imagine the appearance of some other woman on the television screen, say Edwina Curry, to see that Oob look! Margaret 's on will not prevent the listener from picking out the person intended, under the same conditions as previously.

We have tacitly allowed it to be assumed that the speaker/writer, at least, must believe the proper name to be a true description for reference to be successful, if not correct. However, this assumption is wrong. For in ordinary language discourse, "[...] it need not even be the case that the speaker believes the description to be true, but rather that he believes that, by using this expression, he will enable the hearer to pick out the intended referent" (Brown/Yule 1983, 205). Brown/Yule suggest that there are three domains of fact that must be separated out if we are to understand how this can happen: what is in the world; what is in the mind of a person as the representation of the world (a model of the world); and a model of the world formed from a particular discourse, a discourse representation, which may or may not be consistent with that person's prior general model or representation of the world. The prior model, moreover, need not be "right" from the point of view of another person. 
It takes a moment's consideration to realize that in most instances successful communication of propositional content and other information can be effected at the level of discourse representation; it is not necessary for speaker/writer and hearer/reader to share world-models, only discourse representations (cf. the discussion in Brown/Yule 1983, 208-14), and the sources they cite). This makes the philosophical view of the function of proper names difficult to maintain, if not untenable.

From the linguistic point of view, we need carefully to consider the kinds of fact that allow speakers and hearers - or writers and their readers - to establish shared discourse representations. Linguistic facts about proper names and proper nouns obviously will play a part in this, although we think it may not be the major part. The orientation of this inquiry must be neo-Saussurean, carefully examining what individuals do with their language(s) before we try to induce generalizations and formulate a (testable) theory of langue.

\section{Some linguistic facts on proper names}

In this section we list some ordinary language phenomena that we think should play a role in developing a theory of proper names from a linguistic point of view. We shall not go into these matters in detail, for we feel we are still at an exploratory stage of our inquiry.

\subsection{Conditions for naming}

\subsection{1. "Namability"}

The prime condition for names to come into being is that there should be a social need for them. This implies that, in some way or other, things are chosen for naming because they are of special significance to the language user(s) who invent and/or use the names. We might call this the namability criterion. Naming is an aid to human orientation in the environment. To be namable, a thing has to be identifiable for some human purpose. Many things that human beings act on or are affected by, are physical objects of some kind. This explains why a large number of names treated in the literature designate physically perceptible things. We would wish to take a wider view of namability than this, oriented towards discourse representations and discourse functions.

The sorts of physically perceptible things that can be named are:

(i) People: by means of baptismal or first name (Marion, Michael), family names (Wimmer, Burkbardt), dynasty names (Stauffer, Habsburg, Plantagenet), function names (Queen, President, Doctor), nicknames (Sprog, Maichen, Tiny), and many more. Many of these names, particularly 
nicknames, can be impressively rich in structure. One thinks of She who must be obeyed, also written She-wbo-must-be-obeyed, one of the nicknames for a well-known British Prime Minister who also bears as nicknames an acronym $T I N A$, later Tina, relating to one of her supposed favourite sayings, "There is no alternative!"

Groups of people also take names: The Plymouth Brethren, Morriston Male Voice Choir, Die Grüne Liste, ASH, ABBA, Wetwetwet, Mensa. A number of such names show that the group in question is being named as if it were one individual.

All sorts of human institutions (e. g. schools, universities, ministries, offices) and organisations (e. g. teams, private companies) are given proper names.

(ii) Animals, domestic and otherwise. Different kinds of animals seem to have names of typically distinct lexical material. Anyone who has visited Kruft's Dog Show will know that some animal names can be very complex in structure. Most native speakers of English can recognize the sort of animal whose proper names these are: Twinkle, Skyrocket, Rip, Rajah, Poob-Poob, Jezebel.

(iii) Plants: Ena Harkness, Peace, Liebstöckel|Love Lies Bleeding, Vergissmein-nicht|Forget-me-not.

(iv) Places: Geographic names form a particularly large set ranging from names for stars and star systems, through planets, oceans, continents, countries, counties and cantons, fiefdoms, settlements, fields, mountains, bays and rivers and springs, to single rocks.

(v) Time segments: Tuesday, Cbristmas, the Spring, Sonnabend, Fastnachtsdienstag, Buß- und Bettag.

(vi) Natural events: El Niño, The Severn Bore, Hurricane Freddie, The Aurora Borealis, Der Föbn.

(vii) Human-caused events: The French Revolution, The Terror, Der Anschluß, Die Reichskristallnacht, The Night of the Long Knives, Big Bang/The Big Bang (The City event, after the astronomical!)

(viii) Human artefacts: anything of special interest can be given a name, using material from many sources: Concorde, Challenger, The Ark, Royal, Herald of Free Enterprise, Der Goldene Pfeil, Spirit of St Louis.

(ix) Human activities of all kinds can be given names, e.g.

dances The Cage, The Black Bottom

races The New York Marathon, The Olympics, The Milk Run, The Tall Ships, The Grand National, The Le Mans TwentyFour Hours, etc.

games Oranges and Lemons, Mensch ärgere dich nicht, Bobby Kicke The Tin, Hide 'n' Seek

and other rituals of different kinds, e. g.Crossing The Line. 
These are the more obvious categories of things to be named. We have not listed diseases (Legionaires' Disease, Big C, AIDS/Aids), and similar objects of perception that are rather hard to perceive in the "real world" but are nevertheless namable, such as The Point of False Origin, The International Dateline, and The Equator. Clearly, they do not have the same status as fictional names, and cannot therefore lightly be dismissed as having no reference in the world. In fact, a large number of human activities are affected by the things for which these names are used as handy references.

The namability criterion, if an entity fulfils it, allows even the fact that it has no name to be used as a means of forming a name-structure that can be used for reference: e. $g$.

I'll never forget Whatsisname/Wosnim

Did you go out with Thingie last night?

She fell in love with The Man With No Name.

The person who taught geometry to this article's first author used to insist that every map drawn had to have a token of The Doodab to show where North was, but equally possible would have been a name such as Wotchercallit or Wotchmecall to refer to the same thing. Not quite in the same league, but nevertheless in need of an explanation within a general theory of proper names, is the name given to itself by a company renting out services and equipment to clear blocked drains: If You Want a Tbingum$m y$, Ring $M e$.

This brings us to the question of whether proper names have to have a physical referent at all. Can second and more interestingly third order entities be referred to, and if so can this involve use of proper names (on entities, cf. Lyons 1977, 438-52)? Would it be enough for an entity of whatever order - to have a representation in discourse, for it to be referred to in this way? Our tentative view is that this is a sufficient criterion, so that The Oath of Allegiance, Noun Phrase, Boyle's Law and Not The Nine O'Clock News are proper names in at least some discourses, for example.

\subsubsection{Outline of types}

Setting up a typology of proper names from the linguistic point of view is an obvious prerequisite for further interdisciplinary discussion. There are many different ways to do this, none of which at the moment appears satisfactory by itself.

Classifying namable entities does not look to be a long-term guarantor of better understanding, though it does offer one way of appreciating the complexity of the phenomenon of naming. Collecting name-forms also helps us to appreciate that both the philosophical and the linguistic 
approaches to the subject have been seriously deficient. We would like to have a typology of discourses as well as of speaker-listener and writerreader roles and situations as a basis from which to develop a typology of proper names. We will also have to attend to matters of language variety and variation too (cf. Quirk et al. 1985, 15-33).

There seems no reason at the moment for excluding fictional proper names from the typology, any more than there is for not including things like book-titles, registered trademarks, acronyms and abbreviations, for example. These will possibly be defined as names within certain discourse types, once we have established what these are.

\subsubsection{Situations of use}

Proper names are used in ways otherwise than to perform acts of reference. These need to be taken into account in a properly constituted theory. Some of the factors to bear in mind are: other kinds of act that involve proper names; the medium of communication being used; socially instituted procedures that involve proper names.

Thanks to the work of Searle, we linguists are now much more aware than we used to be of the different kinds of act that can be performed through uttering certain forms of words. Proper names are used in a number of these, such as inquiry (Are you Michael Evans? Does a Michael Evans live bere?) swearing (I, Rainer Wimmer, bereby swear ... so belp me God), greeting (Hallo, Eva), leave-taking (Bye bye, Rainer), calling attention (Marion, look out!), and so on. In none of the above examples could the addresser be said to be referring.

The kinds of act will vary according to the medium being used, and this may introduce other variation, such as in the form of the proper name used. So in the written medium, for example, putting one's name on documents can signify various things: that one has read them (but not necessarily that one agrees with their content), that one approves them (without having written them oneself) either on one's own account or someone else's, that one has written them and vouches for the honesty/ quality/truth of their contents, etc. Names are signed on letters, written in as (part of) greeting formulae or as part of the address on the outside of letters, etc. They show ownership (or putative ownership) when written on the inside covers of books; they validate certain kinds of socially important documents, such as driving licences, bank cards and passports, and can be worth a lot of money when on a cheque.

Different social procedures are sanctioned by the use of proper names of various kinds. Baptism is these days not as common as it once was, but name-registration at birth, marriage and death is increasingly important in most societies, and different societies exercise different amounts of control over which names are used. In Germany, for instance, there are 
many more restrictions than in Britain on the type of name that can be registered for a child after birth. Similarly, the procedure of name-changing on marriage is regulated very carefully, but in a way different from that in Britain or America. The state may thus be influential in deciding what material is used in name-structures. Changing name by deed-poll is also a procedure that is being increasingly invoked with the growing importance of bureaucratic state documentation of its citizens. In increasingly frequent circumstances, names can be treated as legally protectable property, as in registered company names and trade names/marks.

In some societies, social or formal state control over naming can be exercised to the advantage or disadvantage of selected minorities being discriminated. Some categories of people either may not be, or must be, named with certain name-structures. One thinks here of the restrictions placed on French de and German von in names at earlier periods; of the forced registration of Jews as either Sarab or Israel in Nazi Germany; of the prohibition against titles of nobility in the USA, leading to such titles used as baptismal names, e. g. Duke Ellington; and in Moslem countries, the restriction on bearing the name Haj, to those who have visited Mecca. The whole question of name-giving and name-getting or name-changing is culture-bound, showing considerable variation from one community to another, and is as yet imperfectly understood.

\subsubsection{Linguistic systemic factors}

Formal aspects of natural language codes must be taken into account in a linguistic theory of names. Much more remains to be found out and said about the syntax, semantics and lexical morphology of proper names than we have so far achieved.

The syntactic structure of names is not well understood, as we implied in 2.2. (2.2.1. and 2.2.2.). The limitations on structural variety usually supposed in grammatical taxonomies are too narrow, as many of our examples show. Proper name structures may be of any size up to that of sentences (e.g. It's That Man Again, the proper name of a wartime radio programme, whose acronym became its nickname: ITMA). Even the basic assumption that name-structures are found only in the domain of NP needs careful scrutiny: the relation between name and general lexical material, in particular the processes of derivation such as verbalization, adjectivization, etc., may lead us to modify this stance. For example, a recent television series entitled The Story of English told in one of its episodes, on Celtic-English language contact, how during the time of Cromwell Irish people imprisoned or captured by the English were Barbadoed, i. e. sent as forced colonists to the West Indian island of Barbados. This is not a unique example: cf. the verbs Shanghai, Harvey Smith and Boycott in English, all of which first appeared with capital letters, and $B /$ 
balkanisieren in German. Are these verbs to be treated as proper names, for second-order entities perhaps? If so, then clearly the NP-domain theory is in trouble.

In formal semantics it has been realized for some time that semantic structural relations such as synonymy, antonymy and hyponymy are disturbed by proper names: the normally revealing logical tests of tautology, entailment and contradiction, for instance, are blocked or modified by such material. E. g. uttering This is a red bridge logically commits the utterer to the same truth-value as is born by This is a red thing and This is a bridge, but This is a Red Bridge (assuming that one of several places with the same name is being referred to) does not logically entail the same truth-value for either of the above statements; we might look at the place and find that it was some other colour or that there was no sign of a bridge in the vicinity, since both waterways and roadways can disappear over time. With the known vagaries of linguistic sound change and folk etymology, we could not even be certain that the spot had once had a bridge. Statements like That female Blackbird is brown are not contradictions, but one like That female black bird is brown certainly are (cf. Coates 1988, and Cruse 1986, $183 \mathrm{ff}$. for a discussion of related points). With a lexeme like baker we would expect certain other lexemes to collocate, such as flour, cake, bread, etc., but we would not expect the same with the proper noun Baker.

The relation between proper names/nouns and the general lexicon is also imperfectly understood. In German, for example, adjectives derived from place-names are standardly written as other adjectives, with initial minuscule, but in English this is not so. Compare Bayern - bayrisch with Bavaria - Bavarian. The exception in German is if the adjective is part of a proper name structure, e. g. a nickname or a brand-name: Bayrisch Karl, Bayrisches Bier.

There seem to be few restrictions on names passing into general vocabulary and entering into normal lexical derivation processes: Thatcherism, Reaganomics, and Genschergate each instantiate different word-formation processes. Do they have a place in a theory of proper names? We think so.

\section{Summary and conclusion}

Our view is that Searle's understanding and use of the term proper name, while undoubtedly appropriate in the context of the Frege-Russell tradition, is in some ways too restricted for what he says to be of general help to linguists. Principally, he understands by proper name an expression that can designate one and only one perceived object, or something treated 
as if it is one perceived object. One could perhaps say that Searle has not gone any further than Russell and Frege in distinguishing names from words.

The conditions for reference, on the other hand, are now better understood as a result of Searle's work: the Speaker intends the Hearer to understand what said Speaker intends. This insight relates, however, to a general level of felicity conditions for speech acts rather than having anything specifically to do with proper names (in the linguistic sense of the term). Moreover, it is relevant not only for natural language proper names, but for all grammatically describable nominal groups whose tokens can be used to designate any definite objects in a situationally adequate way. And as we have shown, natural language proper names are not used exclusively or even perhaps principally to refer.

A comprehensive linguistic theory of proper names will have to include a version of the general rules of reference that Searle has developed in relation to all the possible expressions suitable for referring. That goes without saying. But first of all, the specifics of proper names, about which Searle has little to say, should be properly treated. This is clearly still a major outstanding task for linguists and philosophers.

As we have shown, large areas of knowledge still remain to be more fully explored and properly systematized. The syntax of proper names is not well understood, particularly in the relationship between proper names and proper nouns. Semantically, as we have seen, it is not a straightforward matter of logical class-inclusion. Other problems which need to be examined are the significance or otherwise of the definite article; the attributive and appositive relations revealed in first and family names; the processes by which names are on the one hand drawn from the available, "everyday lexicon" of a community, and on the other hand exploited in the making of new material for that lexicon; another area for future work would be not only the act(s) but also the social functions of name-giving in societies. We do not believe that this task-list is exhaustive.

We foresee that a new orientation in research on proper names will lead to a more adequate and comprehensive understanding of the phenomena. In particular, we propose that a pragmatics-oriented theory of proper names is necessary. A fixation on truth value functionality as a way of characterizing the language-world relation in this case does not seem to be the best way forward. The bow of the relation varies according to the situation, and is a matter decided by speakers (or writers), possibly with the sanction of a language-using community to back them.

Linguists and philosophers interested in language will not understand the specifics of proper names until we encompass this goal. While Searle's work does not, in our view, go far enough along the road to reach it, we nevertheless value his contribution for helping us to see that such a goal exists. 


\section{References}

Alexander, L. G. (1988), Longman English Grammar. London.

Althaus, H. P./Henne, H./Wiegand, H. E. (eds.) (1980), Lexikon der Germanistischen Linguistik. Tübingen.

Brown, G./Yule, G. (1983), Discourse Analysis. Cambridge.

Coates, R. (1988), "The semantics of proper names." In: Cognitive Science Research Paper Serial No. CSRP 127. University of Sussex at Brighton. Mimeo.

Cruse, D. A. (1986), Lexical Semantics. Cambridge.

Debus, F. (1980). “Onomastik.” In: Althaus, H. P./Henne, H./Wiegand, H. E. (eds.) (1980), Lexikon der germanistischen Linguistik. Tübingen, 187-98.

Dummett, M. (1973), Frege: Philosophy of Language. Worcester.

Frege, G. (1966), "Über Sinn und Bedeutung." In: Patzig, G. (ed.), G. Frege: Funktion, Begriff, Bedeutung. Fünf logische Studien. Göttingen, 40-65. (First published 1892.)

Huddleston, R. (1984), Introduction to the Grammar of English. Cambridge.

Kripke, S. A. (1980), Naming and Necessity. Cambridge, Mass. (Lectures first given 1970).

Linacre, T. (1533), Rudimenta grammatices Thomae Linacri ex Anglico sermone in Latinum versa, interprete Georgio Buchano Scoto. (First ed. c. 1512). Paris.

Linsky, L. (1967), Referring. London.

Lyons, J. (1977), Semantics. Vols. 1 and 2. Cambridge.

Marsh, R. C. (ed.) (1956), Bertrand Russell: Logic and Knowledge. Essays 1901-1950. London.

Padley, G. A. (1976), Grammatical Theory in Western Europe 1500-1700. Cambridge.

Patzig, G. (ed.) (1966), G. Frege: Funktion, Begriff, Bedeutung. Fünf logische Studien. Göttingen.

Quirk, R./Greenbaum, S./Leech, G./Svartvik, J. (1985), A Comprehensive Grammar of the English Language. London.

Rheinwald, R. (1988), Semantische Paradoxien, Typentheorie und ideale Sprachen. Berlin.

Russell, B. (1905), "On Denoting." In: Marsh, R. C. (ed.) (1956), Bertrand Russell: Logic and Knowledge. Essays 1901-1950. London, 41 - 56. (First published in: Mind, 14 (1905), 47993).

Schwayder, D. S. (1961), Modes of Referring and the Problem of Universals. Berkeley/Los Angeles.

Searle, J. R. (1969), Speech Acts. An Essay in the Philosopby of Language. Cambridge.

Searle, J. R. (1983), Intentionality. An Essay in the Philosophy of Mind. Cambridge.

Sørensen, H. S. (1963), The Meaning of Proper Names. With a Definiens Formula for Proper Names in Modern English. Copenhagen.

Strawson, P. F. (1950), “On Referring”. In: Mind, 59, 320-44 (Repr. in: Strawson, P. F. (1971), Logico-Semantic Papers. London, 1-27.

Strawson, P. F. (1971), Logico-Semantic Papers. London.

Strawson, P. F. (1973), Proper Names. (Paper read at the Catholic University of Leuven, March 1973.)

Strawson, P. F. (1974), Subject and Predicate in Logic and Grammar. London.

Wilson, Thomas (1551), The Rule of Reason, Conteinyng the Arte of Logique. (Eds. 1567, 1580).

Wimmer, R. (1973), Der Eigenname im Deutschen. Ein Beitrag zu seiner linguistischen Bescbreibung (= Linguistische Arbeiten 11). Tübingen. 